\title{
Communication \\ An Open-Source Low-Cost Imaging System Plug-In for Pheromone Traps Aiding Remote Insect Pest Population Monitoring in Fruit Crops
}

\author{
Mark Jacob Schrader ${ }^{1}$, Peter Smytheman ${ }^{2}$, Elizabeth H. Beers ${ }^{2}$ (D) and Lav R. Khot ${ }^{1, *}$ \\ 1 Biological Systems Engineering, Center for Precision and Automated Agricultural Systems, \\ Washington State University, Prosser, WA 99350, USA; mark.schrader@wsu.edu \\ 2 Tree Fruit Research and Extension Center, Washington State University, Wenatchee, WA 98801, USA; \\ peter_smytheman@wsu.edu (P.S.); ebeers@wsu.edu (E.H.B.) \\ * Correspondence: lav.khot@wsu.edu
}

check for updates

Citation: Schrader, M.J.; Smytheman,

P.; Beers, E.H.; Khot, L.R. An

Open-Source Low-Cost Imaging

System Plug-In for Pheromone Traps

Aiding Remote Insect Pest

Population Monitoring in Fruit Crops.

Machines 2022, 10, 52. https://

doi.org/10.3390/machines10010052

Academic Editor:

Antonios Gasteratos

Received: 29 November 2021

Accepted: 22 December 2021

Published: 10 January 2022

Publisher's Note: MDPI stays neutral with regard to jurisdictional claims in published maps and institutional affiliations.

Copyright: () 2022 by the authors Licensee MDPI, Basel, Switzerland. This article is an open access article distributed under the terms and conditions of the Creative Commons Attribution (CC BY) license (https:// creativecommons.org/licenses/by/ $4.0 /)$.

\begin{abstract}
This note describes the development of a plug-in imaging system for pheromone delta traps used in pest population monitoring. The plug-in comprises an RGB imaging sensor integrated with a microcontroller unit and associated hardware for optimized power usage and data capture. The plug-in can be attached to the top of a modified delta trap to realize periodic image capture of the trap liner $(17.8 \mathrm{~cm} \times 17.8 \mathrm{~cm})$. As configured, the captured images are stored on a microSD card with $\sim 0.01 \mathrm{~cm}^{2}$ pixel $^{-1}$ spatial resolution. The plug-in hardware is configured to conserve power, as it enters in sleep mode during idle operation. Twenty traps with plug-in units were constructed and evaluated in the 2020 field season for codling moth (Cydia pomonella) population monitoring in a research study. The units reliably captured images at daily interval over the course of two weeks with a $350 \mathrm{mAh}$ DC power source. The captured images provided the temporal population dynamics of codling moths, which would otherwise be achieved through daily manual trap monitoring. The system's build cost is about $\$ 33$ per unit, and it has potential for scaling to commercial applications through Internet of Things-enabled technologies integration.
\end{abstract}

Keywords: precision agriculture; integrated pest management; codling moth

\section{Introduction}

Integrated pest management (IPM) programs are designed to mitigate agricultural pest pressure through cultural, biological and chemical application techniques towards decreased synthetic pesticide use and enhanced biodiversity. A key aspect to managing pest pressure is accurate and high-throughput monitoring of pest populations $[1,2]$. The development of pheromone lures and insect traps has allowed for better estimation of population densities [3]. Timely data of captured species, number of captures and capture timings from these traps can aid in better pest management decisions [1,4]. However, these traps are manually inspected, which incurs labor costs and reliance on labor availability. This can lead to delayed diagnosis and significant economic losses to the grower.

The industry is therefore moving towards smart solutions, including remote monitoring traps (RMTs). RMTs can improve the temporal resolution of pest population monitoring to better guide crop protection applications [5]. For example, management decisions on codling moth (Cydia pomonella), an important pest in pome fruits, rely on the time span between sequential moth captures [6]. Commercial suppliers (e.g., Trapview, Semios, Pessl Instruments) have begun producing RMTs that capture trap images for real-time pest monitoring. However, commercial RMTs have been adopted hesitantly by growers, as they are expensive and are used at a low trap density. For example, one trap is recommended per hectare of apple orchard block in the state of Washington for codling moth monitoring [6]. However, a commercial service provider tends to install one trap every 4 ha. Furthermore, 
such monitoring is normally part of a service package that costs approximately $\$ 1375 /$ ha, which may not be suitable for all growers [7].

Pertinent to codling moth monitoring, efforts have primarily been focused on classification of insects captured by RMTs [8-11]. While some studies have constructed custom apparatuses [12], the practical application of these traps has yet to be realized due to lack of supporting infrastructure and the hardware cost [5]. To increase adoption and use, these traps need to use hardware components that are widely available, easy to assemble, customizable and cost-effective. Single board computers and microcontroller units (MCUs) are becoming more popular for remote sensing applications in agriculture [13-17]. MCUs often use open-source libraries and programming languages which allow for ease of modification and expansion to a wide range of applications. Integrating MCU technology with RMTs will thus enable relatively easy upgrades to these systems for better resolution, connectivity, data storage and onboard (i.e., edge) computing [5].

In pursuit of a customizable and low-cost RMT, this study was aimed at developing a low-cost open-source MCU-based RGB imaging system that is integrable with existing delta traps used in tree fruit industry for pest monitoring. The sections below describe system design considerations, followed by system development, an ongoing research application and the versatility of the developed system for related pest monitoring applications.

\section{Design Considerations}

The quality of the acquired images, minimal modifications to the geometry of existing traps, high image throughput with limited power source, ease of image transfer and low cost of overall hardware integration were some of the key factors considered in this study. The quality of the acquired images is the most important aspects of the system's design, dictating the efficacy of pest identification and thereby management actions. The image quality can be affected by three primary factors: spatial resolution, lighting and contrast of insects compared to the linear background. As delta trap liners are typically white, they create good contrast for the trapped gray codling moth. With a standard delta trap, this contrast can allow for use of ambient daylight to illuminate the liner, eliminating the need for artificial lighting and the associated power demand.

In a typical design, commercial RMT suppliers focus on image quality optimization by altering the geometric construction of the trap. Impacts of the altered geometry are suspected to compromise the number of insect captures. Delta traps have been optimized in shape and color for optimal codling moth captures $[18,19]$. However, while leading commercial suppliers have adopted aspects of the optimized design (Figure 1b-d), the openings appear to be smaller, potentially inhibiting insect entry and pheromone dispersion. Furthermore, existing phenology models and thresholds have been based on existing delta trap capture rates. Changes in trap geometry may alter the accuracy of these parameters, leading to incorrect management decisions.

Ideally, the entire imaging system would fit inside the peak of the standard delta trap to eliminate trap modifications. However, in order to capture the entire liner in an image, the trap's geometry demands a field of view (FOV) of approximately $97^{\circ}$, which is wider than typical low-cost imagers can provide. As trap geometry must be changed to accommodate a low-cost imager, in this study, the RMT was designed to more closely mimic the current delta trap dimensions $(10.5 \mathrm{~cm} \mathrm{H} \times 19.5 \mathrm{~cm} \mathrm{~W})$ to ensure maximum captures (Figure 1a).

As the RMT is only required to capture images periodically, power consumption needs to be minimal during idle operation. Many available MCU chips are equipped to go into a low-power consumption state (sleep mode) by removing power from unneeded on-chip domains [24]. In sleep mode, the MCU relies on an interrupt to continue operation. An interrupt is an external signal which can be provided by a Real Time Clock (RTC) or another input with an independent battery. Some MCUs are equipped with onboard RTCs which remain powered in sleep mode and provide an interrupt after a predetermined time period. Additional long-term goals include the realization of on-demand imagery data 
transfer from each trap via localized wireless options. Thus, the MCU needs to be capable of wireless network integration through Wi-Fi, among other communication protocols. The plug-in unit also needs to be designed to minimally obstruct insect capture by the trap.

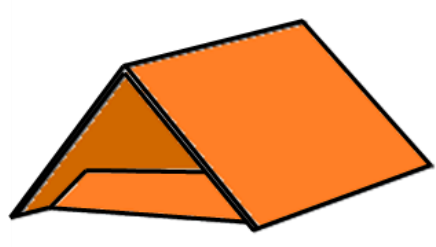

(a)

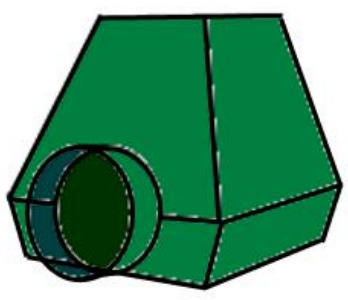

(c)

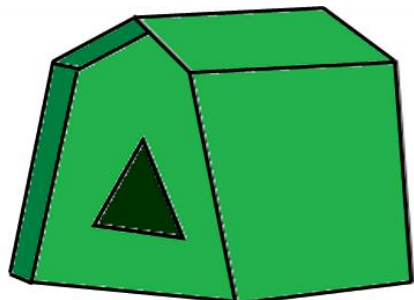

(b)

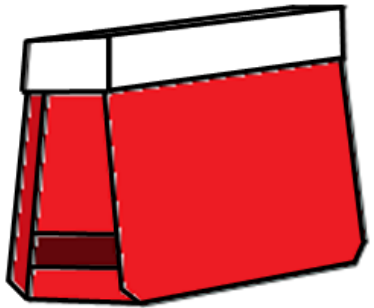

(d)

Figure 1. (a) Sketch of a standard delta trap used for codling moth trapping in pome fruit crops adapted from [20]. Other sketches $(\mathbf{b}-\mathbf{d})$ are adaptations of commercially available remote monitoring traps equipped with imaging systems for codling moth monitoring [21-23].

Finally, the integrated system needed to be low-cost. In this study, we aimed to produce each RMT plug-in for \$30 per trap [25], as it should cover a hectare of orchard and be economical for widespread usage [6].

\section{System Development}

The MCU (Arducam IoTai ESP32 CAM Wi-Fi Bluetooth PSRAM Development Board with Camera Module OV2640, Arducam, Hong Kong, China) selected for this study is equipped with an OV2640 imager of 2-MP resolution $(1600 \times 1200$ pixels $)$ and an integrated RTC, along with Wi-Fi, Bluetooth and Bluetooth Low Energy (BLE) capabilities. The MCU has the ability to switch in and out of sleep modes and enable wireless data transfer. This can enable future Internet of Things (IOT) integration of these traps in a deployed network. For immediate applications, an onboard microSD card module was used for automated data storage. The entire unit was powered by a $3.7 \mathrm{~V}$ DC lithium polymer ion battery pack. The cost of the assembled unit is about $\$ 32.69$ (see Table 1 for detailed cost breakdown).

Table 1. Imaging system plug-in parts breakdown and associated costs.

\begin{tabular}{|c|c|c|c|}
\hline Component & Manufacturer & Purpose & Unit Cost (USD) \\
\hline $\begin{array}{l}\text { Arducam IoTai ESP32 CAM WiFi } \\
\text { Bluetooth PSRAM and development } \\
\text { board with OV2640 camera module }\end{array}$ & $\begin{array}{l}\text { Arducam, } \\
\text { Hong Kong, China }\end{array}$ & Microcontroller /Imager & 19.99 \\
\hline $\begin{array}{c}3.7 \text { v, } 350 \text { mAh Lithium Polymer } \\
\text { Ion battery }\end{array}$ & $\begin{array}{l}\text { Adafruit Industries LLC., } \\
\text { New York City, NY, USA }\end{array}$ & Power & 5.95 \\
\hline $180^{\circ}$ fisheye clip on lens & $\begin{array}{c}\text { Walmart, Inc., } \\
\text { Bentonville, AR, USA }\end{array}$ & Fish-eye lens ${ }^{1}$ & 5.99 \\
\hline \multirow[t]{2}{*}{ Clear mini pencil box } & $\begin{array}{l}\text { S.P. Richards Co., } \\
\text { Atlanta, GA, USA }\end{array}$ & Enclosure & 0.74 \\
\hline & & Total $^{2}$ & 32.67 \\
\hline
\end{tabular}

${ }^{1}$ Only the fisheye lens is required from this package. ${ }^{2}$ Excludes standard trap and labor for trap modification. 
The prototype RMT is shown in Figure 2. As assembled, the imaging unit and battery were contained in a waterproof enclosure $(8.3 \mathrm{~cm} \times 18.4 \mathrm{~cm} \times 3.2 \mathrm{~cm})$. To capture the entire liner $(17.8 \mathrm{~cm} \times 17.8 \mathrm{~cm})$ in a single image, the imager would need to be positioned at $19.96 \mathrm{~cm}$ above the liner. However, a fish-eye lens was used to widen the FOV and decrease the required trap height (to $15.5 \mathrm{~cm}$ above the liner). The peak of a standard delta trap does not lend itself to installation of an imaging sensor parallel to the liner. Thus, a trapezoidal corrugated plastic structure was used as a support inside the main housing. The main housing was constructed of two delta traps stacked as shown in Figure 2. The upper section of the main housing served to protect the electrical components from solar radiation and related heat exposure, and the lower section contained the trap liner.

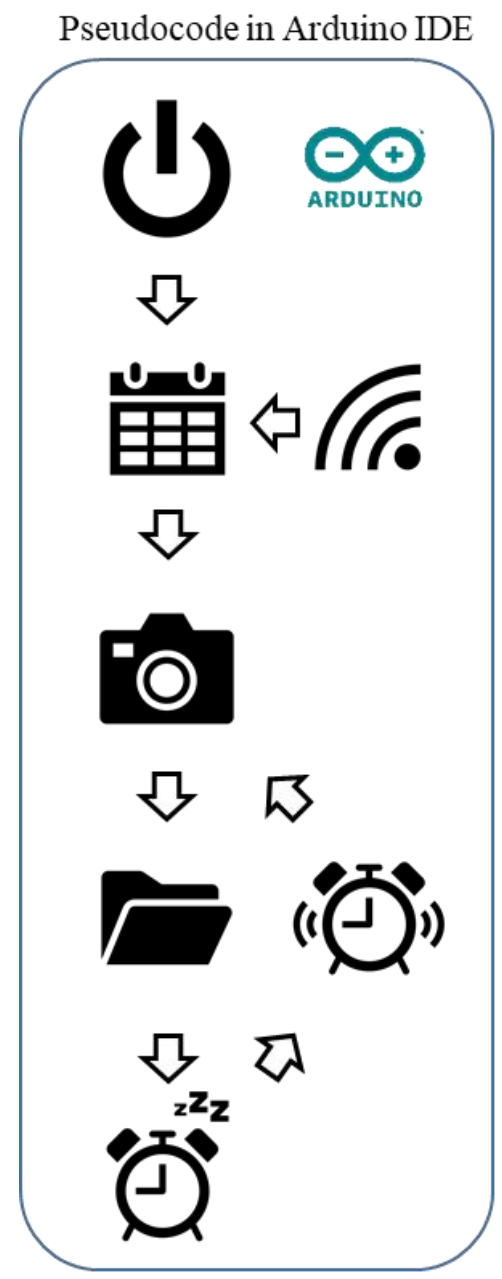

Key components of $\mathrm{MCU}$

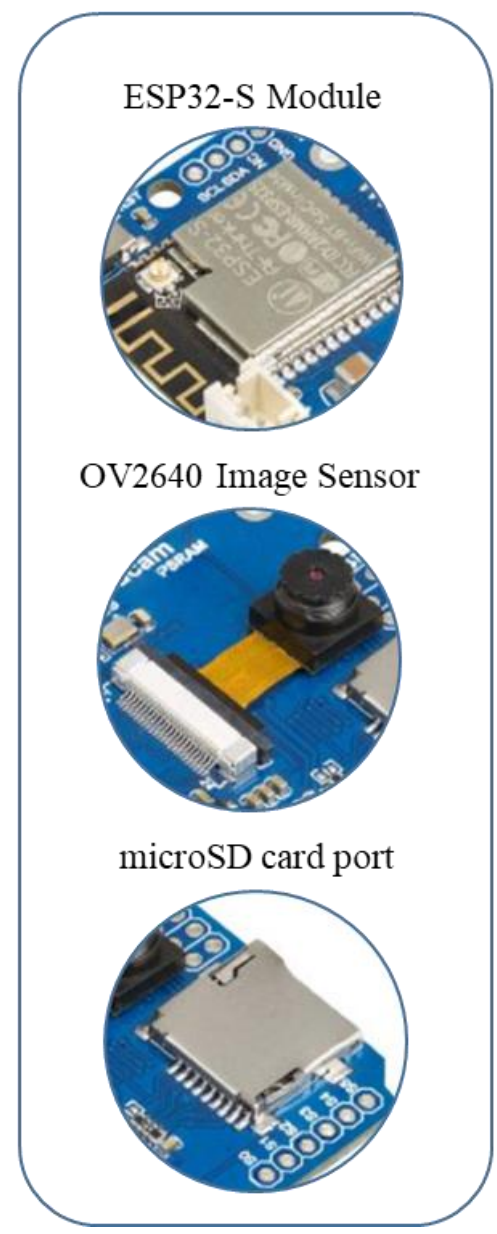

Imaging unit installed in trap

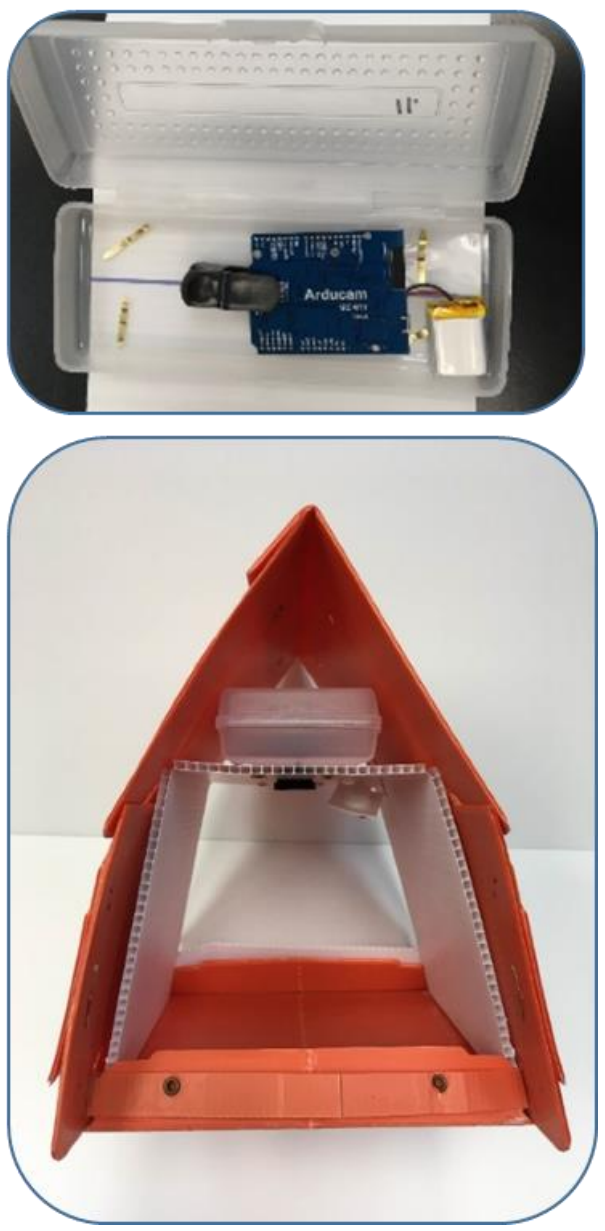

Figure 2. Plug-in RGB imaging system installed in a standard delta trap with inserts illustrating MCU and imager.

The hardware is programmed in Arduino IDE with a customized algorithm to capture one image per day. This allows for monitoring individual moths' arrival dates and temporal progression of insect capture. The codling moth is active at dusk, and to a lesser extent, at dawn, so 10:00 a.m. was chosen for image capture to provide both sufficient light and a complete daily activity cycle. To track the date of capture, the RTC must first be synced with local time. For this purpose, before field installation, the MCU was configured to retrieve local time from a Wi-Fi connection and write it to a "time" structure with date and time stamps (Figure 3). Omission of this step leads to image timestamps beginning at the UNIX epoch. As this MCU's RTC does not operate on an independent battery, it needs to be reset every time the system is restarted. 


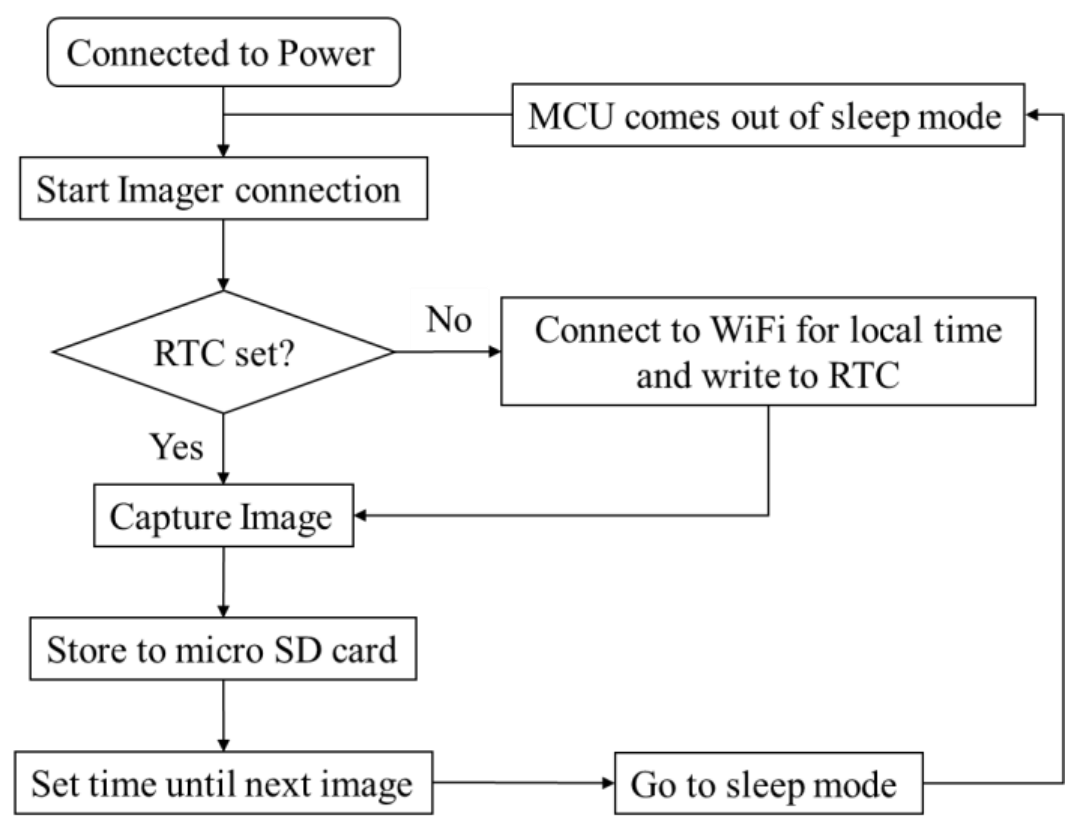

Figure 3. Functional operational flow diagram of developed remote trap monitoring system. RTC: Real Time Clock; MCU: Microcontroller unit.

After the RTC is set, the system then captures an image and stores it as a JPEG file to the microSD card. The MCU then sets the time until next image capture and enters deep sleep mode [25]. In deep sleep mode, only the RTC continues to draw power from the battery. Upon awakening, the code verifies that a "time" structure has been created and contains numeric values which bypasses connecting to Wi-Fi, as the RTC does not need to be reset. Reliance on the RTC for timekeeping can cause drifting from actual local time, however this drift is relatively inconsequential for daily image captures. For each image capture, the MCU is active for approximately $15 \mathrm{~s}$ before returning to sleep mode. With a $350 \mathrm{mAh}$ DC power source, the developed RMTs can sustain field operations for as long as 15 days, exceeding the time required for the ongoing research.

\section{System Evaluation}

The developed RMT is currently being used in a multiyear research study that requires daily counts of captured codling moths. In the 2020 field season, 20 units were hung in apple (cv. Fuji and Granny Smith) canopies in a commercial orchard using standard delta trap installation materials (Figure 4).

For the field install, the MCU was programmed as described above to capture one image per day during daylight hours. The RMTs were collected from the field 15 days after installation to gain insights on the behaviors of mating populations. Individual codling moths were identified on the collected trap liner; images were compared to determine date of arrival for each moth. This information successfully provided daily recapture rates and dispersal from a single release event.

Two of the 20 units $(10 \%)$ installed in the field experienced failure due to broken battery leads. The remaining 18 traps successfully acquired images over the course of 15 days. Only $2.6 \%$ of the imagery data were not captured over the study period due to three units experiencing premature battery depletion after 11, 13 and 14 days. Furthermore, as seen in the images (Figure 5), system installation can be slightly off-centered in the current construction, which can be eliminated with precision manufacturing techniques. The captured images were stored as $320 \times 240$ pixels with a spatial resolution of $0.1 \mathrm{~cm}$ pixel $^{-1}$, which was sufficient for evaluating individual moth capture dates. 


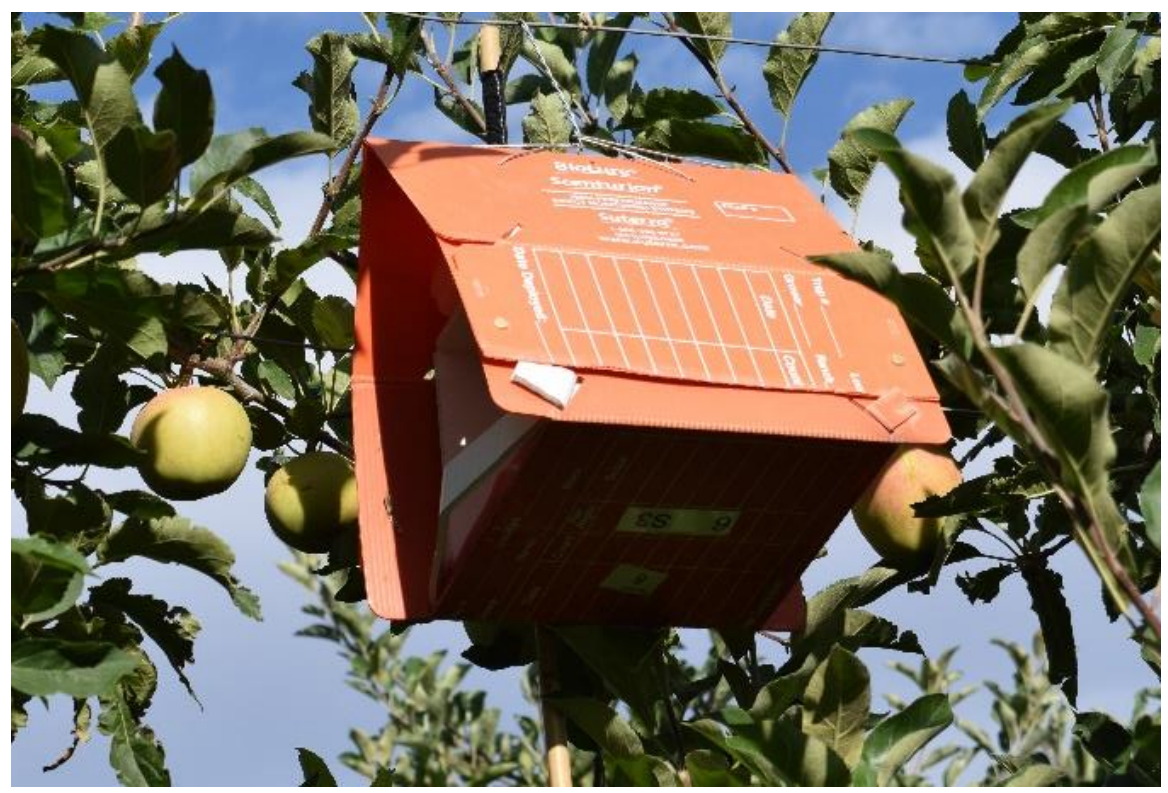

Figure 4. Imaging system plug-in retrofitted in a delta trap installed in apple canopy.
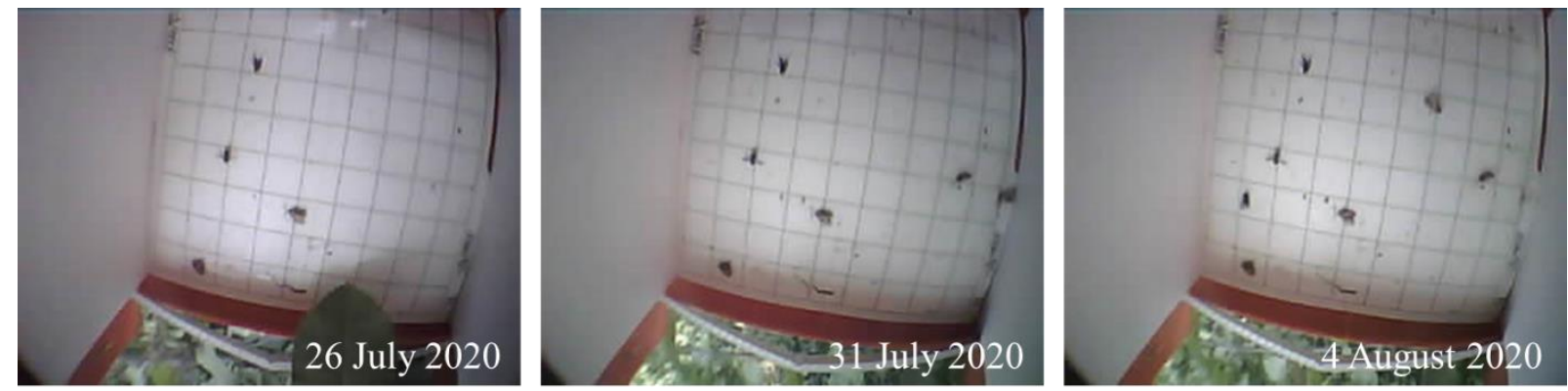

Figure 5. Experimental field images captured by the monitoring system plug-in for a trap over the 10-day period.

\section{Future Scope: Scalability for Other Application Domains}

Towards IPM automation using RMTs, computer vision algorithms can automate the moth species' identification and counting. Ding and Taylor [8] have developed a neural network for moth classification with images of $640 \times 480$ pixel resolution in a commercially available RMT. Though undisclosed, it is estimated that the spatial resolution for Ding and Taylor [8] was between 0.03 and $0.05 \mathrm{~cm} \mathrm{pixel}^{-1}$. To use collected images in such a network, the resolution of the captured images can be improved programmatically to $800 \times 600$ pixels to realize spatial resolution of $0.04 \mathrm{~cm} \mathrm{pixel}^{-1}$.

The system had adequate battery life for the discussed research application; therefore, in-field charging (i.e., solar power) was not pursued. However, an important aspect of the selected MCU is the onboard battery charger which may be integrated with a low-cost solar panel. The selected $\mathrm{MCU}$, in its current configuration, consumes approximately $0.24 \mathrm{~mA} / \mathrm{h}(5.76 \mathrm{~mA} /$ day) [25]. Assuming a minimum of $12 \mathrm{~h}$ of daylight during the growing season, a small solar panel (e.g., Round Solar Panel Skill Badge-5 V/40 mA, \$2.95, Adafruit Industries, New York City, NY, USA) will suffice for sustained system operation.

Concurrently to this study, Wahl and Zhang [25] were working on the potential of creating an IOT network using the selected MCU for agricultural data collection. The study proposed BLE communication between the MCU nodes and a central MCU gateway for uploading images to the open-source Google platform "firebase." However, for codling moth monitoring, it is recommended to install one trap per hectare [6]. With square plots, the traps would be approximately $100 \mathrm{~m}$ apart, which is the maximum range of BLE 
transmission in optimal conditions [25]. The growing canopy foliage may further reduce this range. Furthermore, as rural agricultural communities have poor Internet connectivity and limited wireless infrastructure, uploading to a cloud network from the field is not yet practical $[5,10,26]$.

To address in-field Internet connections, recent studies have investigated accessing in-field sensor data remotely via unmanned aerial vehicles $[27,28]$. The primary concern for these systems is the need for an external signal to activate the sensor, which requires an onboard receiver that is constantly scanning for an activating signal. As power consumption is a challenge, [27] investigated two passive signal receivers for activating the sensing node. A radio frequency (RF) signal was reported to have a larger range and lower consumption compared to an infrared signal. Integration of a RF receiver could be useful for groundbased data collection as well. As codling moth traps are placed in the upper $1 / 3$ rd of the canopy [6], remote activation and data collection using the same protocol as described above could reduce data collection time and allow coverage of greater areas. Integration of passive receivers into sensing nodes may enhance early adoption of RMTs.

The developed RMT, therefore, can serve as an intermediary during the transition to better Internet connectivity. A low-cost RF receiver can be installed on a system which, upon receiving a signal from another BLE-enabled device with RF transmitter, will (i) awaken, (ii) take an image and (iii) advertise that image until it has been received by the client device; then, (iv) it will stop advertising and (v) return into the deep sleep state. While an additional device for RF transmission may be required, most android devices are BLE-enabled, suggesting potential for a mobile application that facilitates wireless image transfer to a handheld mobile device. The image could then be uploaded to a cloudcomputing platform for automated classification and decision-making when connectivity is available.

\section{Summary}

A low-cost RMT was developed to operate on low power, capturing one image per day. The developed system is being used in a multiyear research study related to codling moth behavior monitoring in apple orchards. The objective of determining the dates of capture for individual moths and thus progression counting of insects from the captured images was successfully achieved in this study. For immediate adoption of RMTs, this system offers reduced data collection time, even when implemented independently of cloud computing networks. The system has potential to be scaled using edge/cloud computing approaches, serving as an IOT sensing node [25] to capture and transmit information for real or near real-time decision making. Furthermore, the developed imaging system plug-in may be integrated into other insect traps for remote population monitoring using the design considerations outlined in this study.

Author Contributions: Conceptualization, M.J.S., P.S., E.H.B. and L.R.K.; methodology, M.J.S., P.S. and E.H.B.; software, M.J.S.; validation, P.S. and E.H.B.; investigation, M.J.S., P.S. and E.H.B.; resources, E.H.B. and L.R.K.; data curation, P.S. and E.H.B.; writing—original draft preparation, M.J.S., P.S. and L.R.K.; writing-review and editing, M.J.S., P.S., E.H.B. and L.R.K.; visualization, M.J.S., P.S., E.H.B. and L.R.K.; supervision, E.H.B. and L.R.K.; project administration, E.H.B. and L.R.K.; funding acquisition, E.H.B. and L.R.K. All authors have read and agreed to the published version of the manuscript.

Funding: This work was supported in part by the USDA National Institute of Food and Agriculture, Hatch projects 1016563 and 0745 , and in part by the Washington Tree Fruit Research Commission Project CP-18-104.

Institutional Review Board Statement: Not applicable.

Informed Consent Statement: Not applicable.

Data Availability Statement: Not applicable.

Acknowledgments: The authors would like to thank Basavaraj Amogi for assistance in sensor selection. 
Conflicts of Interest: The authors declare no conflict of interest.

\section{References}

1. Ehler, L.E. Integrated pest management (IPM): Definition, historical development and implementation, and the other IPM. Pest Manag. Sci. 2006, 62, 787-789. [CrossRef] [PubMed]

2. Barzman, M.; Bàrberi, P.; Birch, A.N.E.; Boonekamp, P.; Dachbrodt-Saaydeh, S.; Graf, B.; Hommel, B.; Jensen, J.E.; Kiss, J.; Kudsk, P.; et al. Eight principles of integrated pest management. Agron. Sustain. Dev. 2015, 35, 1199-1215. [CrossRef]

3. Glen, D.M.; Brain, P. Pheromone-trap catch in relation to the phenology of codling moth (Cydia pomonella). Ann. Appl. Biol. 1982, 101, 429-440. [CrossRef]

4. Higley, L.G.; Peterson, R.K.; Radcliffe, E.B.; Hutchison, W.D.; Cancelado, R.E. Economic decision rules for IPM. In Integrated Pest Management: Concepts, Tactics, Strategies and Case Studies; Radcliffe, E.B., Hutchison, W.D., Cancelado, R.E., Eds.; Cambridge University Press: New York, NY, USA, 2009; pp. 25-32. [CrossRef]

5. Preti, M.; Verheggen, F.; Angeli, S. Insect pest monitoring with camera-equipped traps: Strengths and limitations. J. Pest Sci. 2021, 94, 203-217. [CrossRef]

6. Beers, E.H.; Brunner, J.F.; Willett, M.J.; Warner, G.M. Codling Moth. In Orchard Pest Management a Resource Book for the Pacific Northwest; Good Fruit Grower Yakima: Yakima, WA, USA, 1993; pp. 63-68.

7. Remote Pest Management with Automated Traps. Available online: https://blog.semios.com/remote-pest-management-withautomated-traps (accessed on 10 December 2021).

8. Ding, W.; Taylor, G. Automatic moth detection from trap images for pest management. Comput. Electron. Agric. 2016, 123, 17-28. [CrossRef]

9. Sun, Y.; Cheng, H.; Cheng, Q.; Zhou, H.; Li, M.; Fan, Y.; Shan, G.; Damerow, L.; Lammers, P.S.; Jones, S.B. A smart-vision algorithm for counting whiteflies and thrips on sticky traps using two-dimensional Fourier transform spectrum. Biosyst. Eng. 2017, 153, 82-88. [CrossRef]

10. Cardim Ferreira Lima, M.; Damascena de Almeida Leandro, M.E.; Valero, C.; Pereira Coronel, L.C.; Gonçalves Bazzo, C.O. Automatic detection and monitoring of insect pests-A review. Agriculture 2020, 10, 161. [CrossRef]

11. Bjerge, K.; Nielsen, J.B.; Sepstrup, M.V.; Helsing-Nielsen, F.; Høye, T.T. An automated light trap to monitor moths (Lepidoptera) using computer vision-based tracking and deep learning. Sensors 2021, 21, 343. [CrossRef] [PubMed]

12. Guarnieri, A.; Maini, S.; Molari, G.; Rondelli, V. Automatic trap for moth detection in integrated pest management. Bull. Insectol. 2011, 64, 247-251.

13. Zhao, J.C.; Zhang, J.F.; Feng, Y.; Guo, J.X. The study and application of the IOT technology in agriculture. In Proceedings of the 2010 3rd International Conference on Computer Science and Information Technology, Chengdu, China, 9-11 July 2010; pp. 462-465.

14. Prathibha, S.R.; Hongal, A.; Jyothi, M.P. IoT based monitoring system in smart agriculture. In Proceedings of the 2017 International Conference on Recent Advances in Electronics and Communication Technology (ICRAECT), Bangalore, India, 16-17 March 2017; pp. 81-84. [CrossRef]

15. Vanaja, K.J.; Suresh, A.; Srilatha, S.; Kumar, K.V.; Bharath, M. IOT based agriculture system using node MCU. Int. Res. J. Eng. Technol. 2018, 5, 3025-3028.

16. Ranjan, R.; Khot, L.R.; Peters, R.T.; Salazar-Gutierrez, M.R.; Shi, G. In-field crop physiology sensing aided real-time apple fruit surface temperature monitoring for sunburn prediction. Comput. Electron. Agric. 2020, 157, 105558. [CrossRef]

17. Deepa, B.; Anusha, C.; Devi, P.C. Smart agriculture using iot. In Intelligent System Design; Satapathy, S., Bhateja, V., Janakiramaiah, B., Chen, Y.W., Eds.; Springer: Singapore, 2021; Volume 1171, pp. 11-19. [CrossRef]

18. Knight, A.L.; Larson, D.; Christianson, B. Flight tunnel and field evaluations of sticky traps for monitoring codling moth (Lepidoptera: Tortricidae) in sex pheromone-treated orchards. J. Entomol. Soc. Br. Columbia 2002, 99, 107-116.

19. Knight, A.L.; Fisher, J. Increased catch of codling moth (Lepidoptera: Tortricidae) in semiochemical-baited orange plastic delta-shaped traps. Environ. Entomol. 2006, 35, 1597-1602. [CrossRef]

20. Codling Moth in Utah Orchards. Available online: https://digitalcommons.usu.edu/extension_curall/880/ (accessed on 9 August 2021).

21. Trapview. Available online: https://trapview.com/project/better-earning-apple/ (accessed on 9 August 2021).

22. METOS by Pessl Instruments. Available online: https://metos.at/iscout/ (accessed on 9 August 2021).

23. Technology Takes Field Scouting to the Next Level. Available online: https://www.precisionag.com/in-field-technologies / connectivity /technology-takes-field-scouting-to-the-next-level/ (accessed on 9 August 2021).

24. Yadav, S.; Kapoor, H.K. Lightweight Message Encoding of Power-Gating Controller for On-Time Wakeup of Gated Router in Network-on-Chip. In Proceedings of the 2019 9th International Symposium on Embedded Computing and System Design (ISED), Kollam, India, 13-14 December 2019; pp. 1-6.

25. Wahl, J.D.; Zhang, J.X. Development and Power Characterization of an IoT Network for Agricultural Imaging Applications. J. Inf. Technol. 2021, 12, 214-219. [CrossRef]

26. Khan, S.F.; Ismail, M.Y. An Investigation into the Challenges and Opportunities Associated with the Application of Internet of Things (IoT) in the Agricultural Sector-A Review. J. Comput. Sci. 2018, 14, 132-143. [CrossRef] 
27. Chen, J.; Dai, Z.; Chen, Z. Development of radio-frequency sensor wake-up with unmanned aerial vehicles as an aerial gateway. Sensors 2019, 19, 1047. [CrossRef] [PubMed]

28. Liu, Y.; Dai, H.N.; Wang, H.; Imran, M.; Wang, X.; Shoaib, M. UAV-enabled data acquisition scheme with directional wireless energy transfer for Internet of Things. Comput. Commun. 2020, 155, 184-196. [CrossRef] 